\title{
The predictive role of history of specific phobia disorder and vaginismus in married women
}

\section{ARTICLE INFO}

\section{Article Type}

Analytical cross-sectional study

\section{Authors}

Mehri Nejat MD ${ }^{1,2 *}$,

Sajjad Qolinia Fashalami MSc ${ }^{3}$, Nafiseh Afshari $\mathrm{MSc}^{3}$

${ }^{1}$ Sarem Fertility and Infertility Research Center (SAFIR), Sarem Women's Hospital, Iran University of Medical Sciences (IUMS), Tehran, Iran

${ }^{2}$ Nejat Sexual Disorders Center Iran University of Medical Science, Tehran, Iran

${ }^{3}$ Faculty of Educational Sciences and Psychology, University of Tehran, Tehran, Iran

*Corresponding Author

Address: Agape Sexual Disorders Center \& Sarem Women Hospital, Basij Square Phase 3, EkbatanTown, Tehran, Iran. Postal code: 1396956111

Phone: +98 (21) 44670888 \& +98 (21) 46040339

Fax: +98 (21) 44670432

mehrinejat@yahoo.com

\section{ABSTRACT}

Introduction: Despite vaginismus is a relatively common sexual dysfunction in Iranian women, rare examinations have reported its roots. Therefore, this study was carried out to examine the link between phobia history and vaginismus in women.

Methodology: The statistical population of this descriptive-correlational study comprises of married women who refer to Agape Sexual Disorders Center and the offices of gynecologists in Tehran. Of the 168 patients who were sampled, 102 had primary vaginismus and 128 had a history of animal, natural environment, blood, and injections phobia. Evaluation tools involved: 1- A blood test to check for anemia and thyroid problems, 2- Physical and genitals examination by a gynecologist 3Clinical interview by a psychiatrist based on DSM5 for mental disorders and phobia 4- A 20-Questions Questionnaire on Female Sexual Function Index (FSF1) for sexual evaluation and diagnosis of vaginismus. 5- A researcher-made questionnaire for demographic characteristics. The data were examined by statistical correlation and logistic regression tests.

Results: The results reveal a significant relationship between phobia and vaginismus $(\mathrm{p}=0.001)$. Therefore, the impact of phobia on the probability of vaginismus is positive.

Conclusion: Based on the findings, we can conclude that women with a history of phobia can be prevented from developing vaginismus by phobia therapy and required training, thus leading to sexual satisfaction in couples.

Keywords: Vaginismus, phobia, fear of vaginal penetration, fear of penetration, failure of intercourse. 
نتيجه

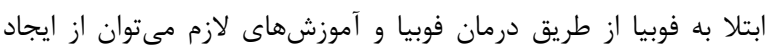

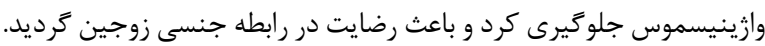
كليد وازمها: وازينيسموس، فوبيا، ترس از نفوذ وازن، ترس از دخول، ناكامى در وصال

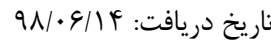
تاريخ يذيرش:

*نويسنده مسئول: مهرى نجات

مقدمه

مهرم ترين ملاك تعيين خانواده سالم، رضايت زوجين از ازدواجشان است

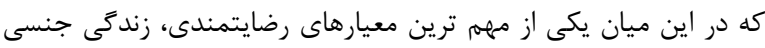

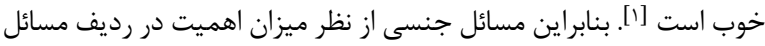

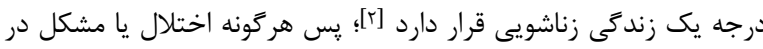

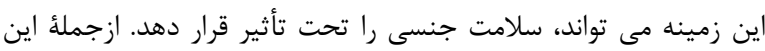

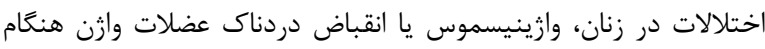

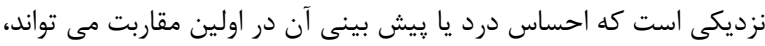

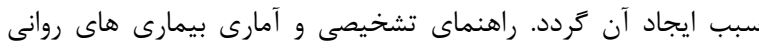

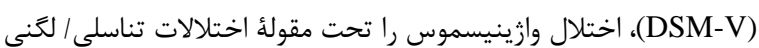

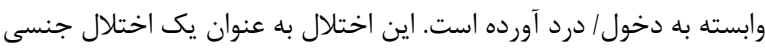

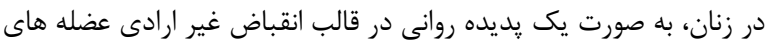

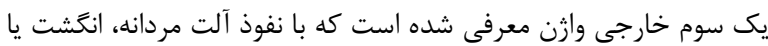

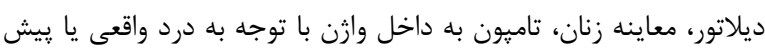

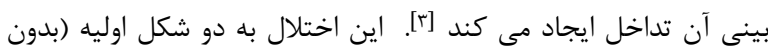

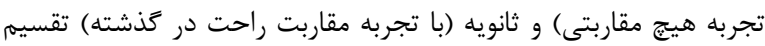

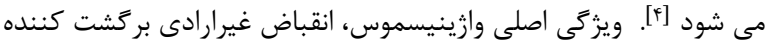

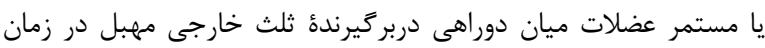

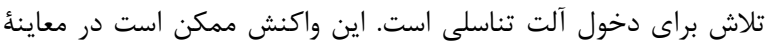

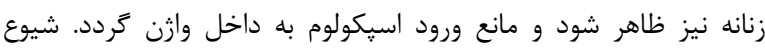

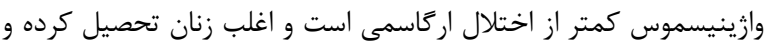

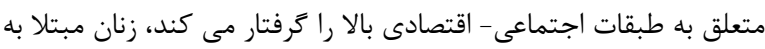

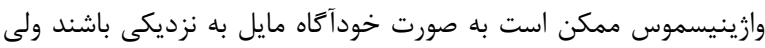

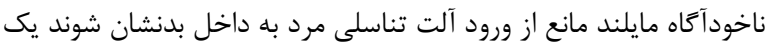

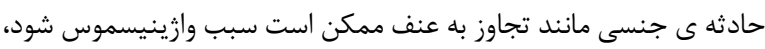

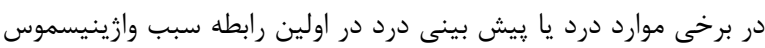

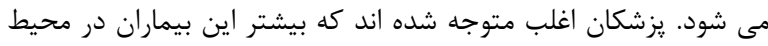

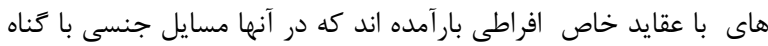

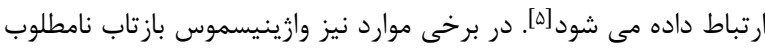

نقش بيشگويى كننده سابقه ابتلا به فوبيا خاص با وازينيسموس در زنان متأهل

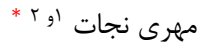
' مركز تحقيقات بارورى و نابارورى صارم، بيمارستان فوق تخصصى صارم،

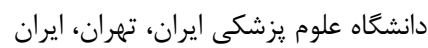

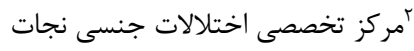

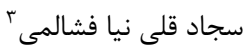
"ّانشكده علوم تربيتى و روانشناسى دانشعاه تهران، تهران، ايران نفيسه افشارى r دانشكده علوم تربيتى و روانشناسى دانشعاه تهران، تهران، ايران

جكيده مقدمه: اخرجه وازينيسموس يك اختلال عملكرد جنسى نسبتاً شايع در زنان ايرانى است، اما مطالعات كمى در مورد علل آن گزارش شده است.

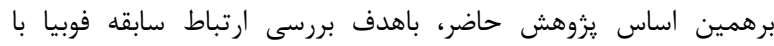

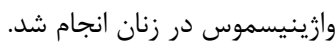
روش: در اين يروهش توصيفى - همبستخى جامعه آمارى شامل زنان متأهل

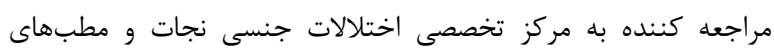

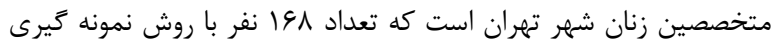

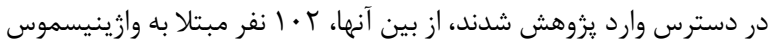

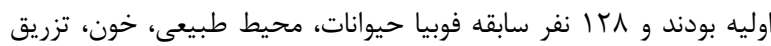

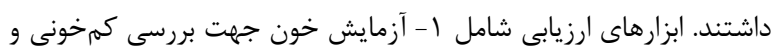

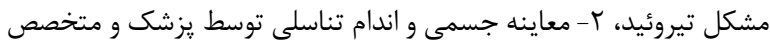

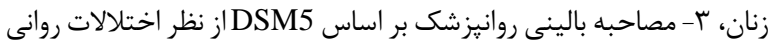

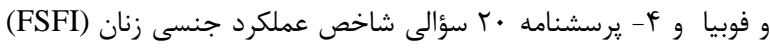

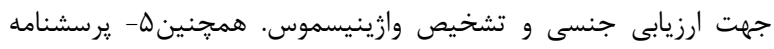

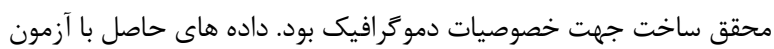

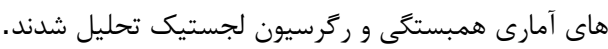

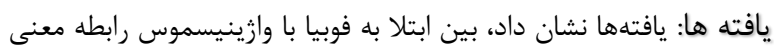

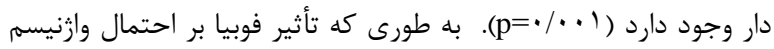

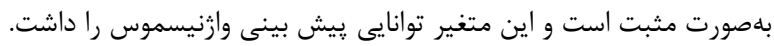

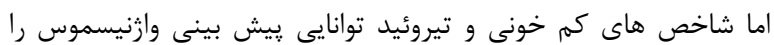
نداشتند. 
با توجه به اينكه ييامدهاى منفى اختلال وارينيسموس شامل ازدواج به

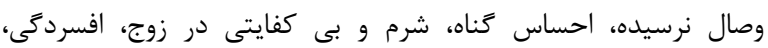

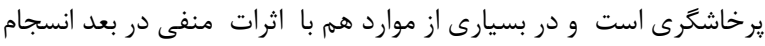

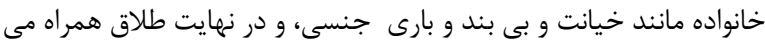

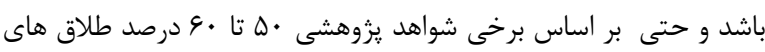

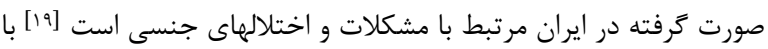

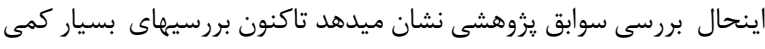

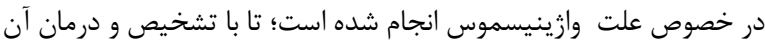

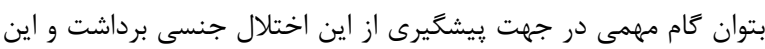

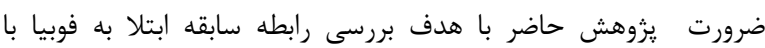
وارينيسموس در زنان مشخص مى كند

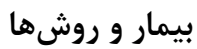

روش تحقيق، توصيفى-همبستكى است ـ جامعه آمارى شامل زنان منان متأهل

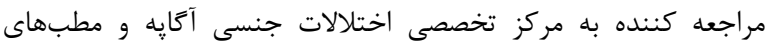

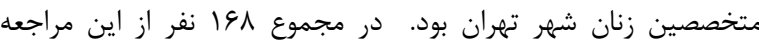

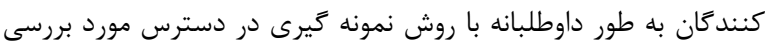

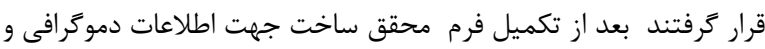

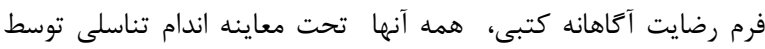

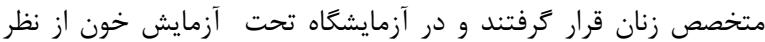

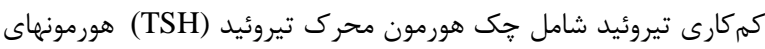

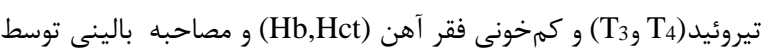
روانيزشك براساس ، يرسشنامه شاخص عملكرد جنسى زنان (FSFI)

ميل و تلاش مكرر براى دخول داشته و توسط مصاحبه بالينى و يرسشنامه

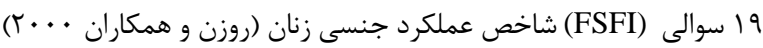

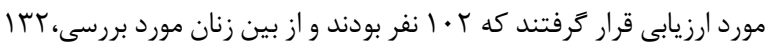

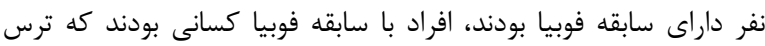

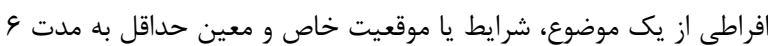

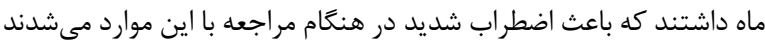

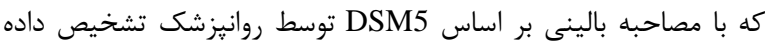

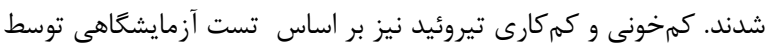

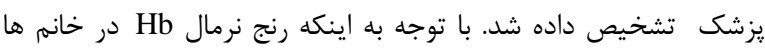

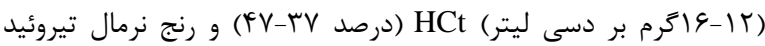

$(\mathrm{TSH} \cdot / \varepsilon$ - $\varepsilon)$

معيارهاى ورود: همه خانمهاى متأهل كه حداقل 9 ماه از ازدواج آنها كذشته بود معيارهاى خروج: خانمهايى با اختلالات شديد روانى، بيمارى شديد جسمى

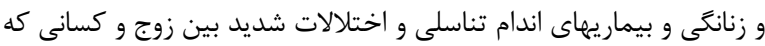
قصد جدايى داشتند.
بودن روابط است. اكرشريك جنسى زن از لحاظ عاطفى از او سواستفاده

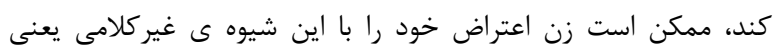

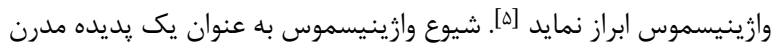

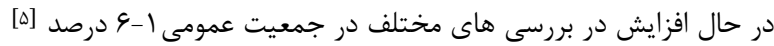

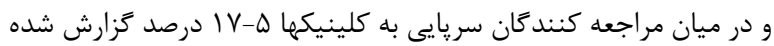

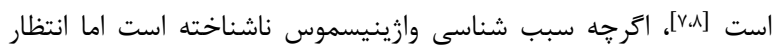

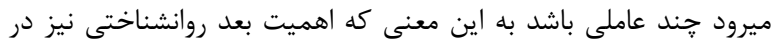

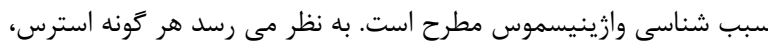

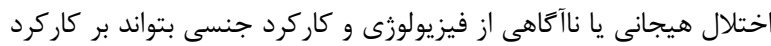

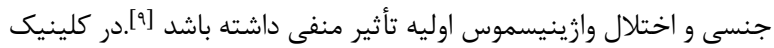

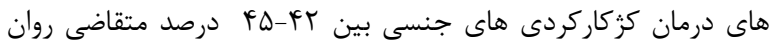

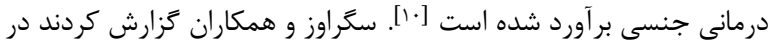

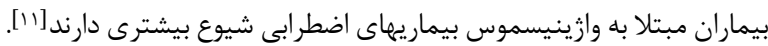

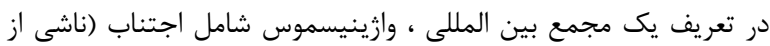

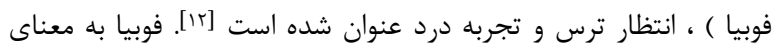

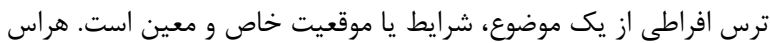

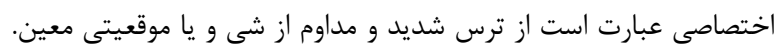

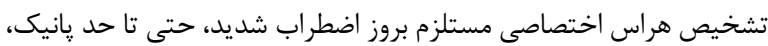

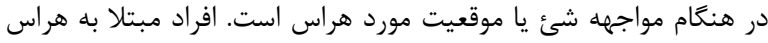

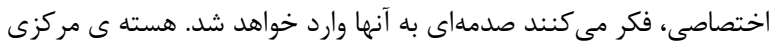

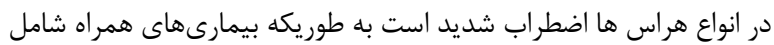

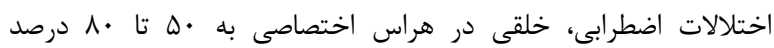

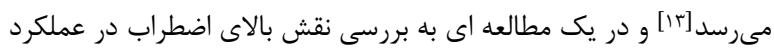

جنسى كيفيت عملكرد جنسى زنان را محدود مى كند و يا منجر به اجتناب

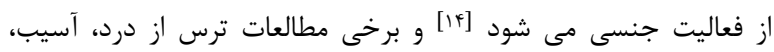

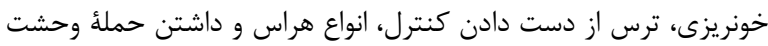

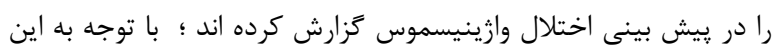

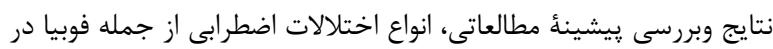

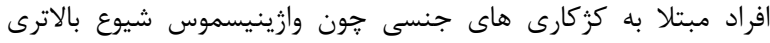

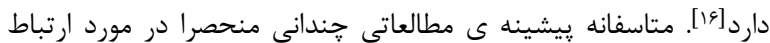

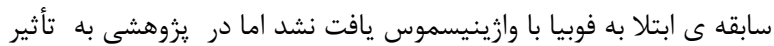

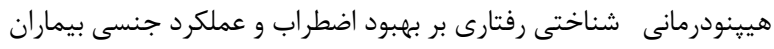

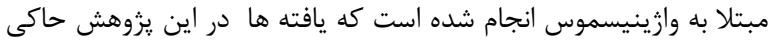

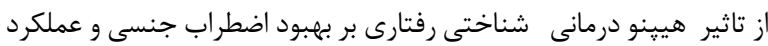

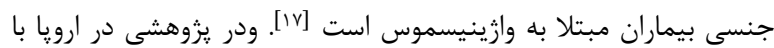

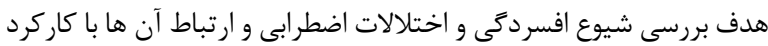

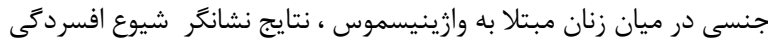

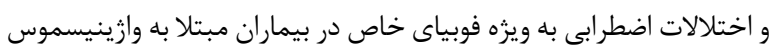

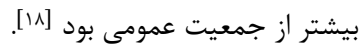




\begin{tabular}{|c|c|c|c|}
\hline ( & $\Delta G$ & يك سال & \multirow{8}{*}{ مدت تاهل } \\
\hline $\mathrm{IV} / \mathrm{A}$ & $r \cdot$ & دو سال & \\
\hline $1 \pi / 9$ & r & سه سال & \\
\hline $9 / 0$ & 19 & جهار سال & \\
\hline $\mid r / 4$ & rI & ينج سال & \\
\hline$\Lambda / r$ & If & بين ينج تا • ا سال & \\
\hline$F / f$ & v & بين •ا سال ها سال & \\
\hline$\cdot 19$ & 1 & بالاى ها سال & \\
\hline$\Delta T / V$ & 19 & خوب & \multirow{3}{*}{ رابطه با همسر } \\
\hline$r V / q$ & $g f$ & متوسط & \\
\hline $1 / 9$ & 10 & بد & \\
\hline VTr & $\Delta V$ & بله & \multirow{2}{*}{ قصد باردارى } \\
\hline $9 \Delta / V$ & 111 & خير & \\
\hline $1 \cdot 11$ & IV & بله & \multirow{2}{*}{ بيمارى جسمى } \\
\hline 19/9 & $|0|$ & خير & \\
\hline $1 \cdot 11$ & IV & بله & \multirow{2}{*}{ كم خونى } \\
\hline $19 / 9$ & 101 & خير & \\
\hline$V / V$ & IT & بله & \multirow{2}{*}{ كم كارى تيروئيد } \\
\hline $9 T / \pi$ & 100 & خير & \\
\hline VG/T & $\mid r \Lambda$ & بله & \multirow{2}{*}{ فوبيا } \\
\hline$r / \Lambda$ & r. & خير & \\
\hline r $/ \mathrm{V}$ & $1 \cdot r$ & بله & \multirow{2}{*}{ وازينيسموس } \\
\hline $81 / \pi$ & $9 \Delta$ & خير & \\
\hline
\end{tabular}

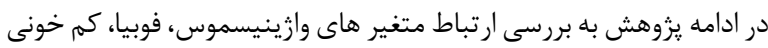

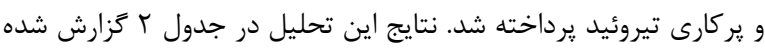

است.

جدول ا. ارتباط بين وازينيسموس، فوبيا، كم خونى و يركارى تيروئيد

\begin{tabular}{|c|c|c|c|c|c|c|}
\hline \multicolumn{2}{|c|}{ كم كارى تيروئيد } & \multicolumn{2}{|c|}{ كم خونى } & \multicolumn{2}{|c|}{ فوبيا } & \multirow[t]{2}{*}{ متغير } \\
\hline sig & $\mathrm{r}$ & sig & $r$ & sig & $\mathrm{r}$ & \\
\hline.$/ 919$ & $.1 . .1$ &.$/ T I$ & $.1 \cdot v q$ & $.1 . .1$ & ***/QHT & والرينيسموس \\
\hline
\end{tabular}

همانكَونه كه در جدول r مشاهده مىشود ارتباط بين وازينيسموس با فوبيا

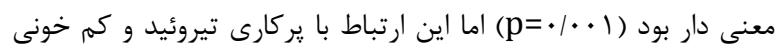

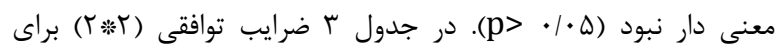

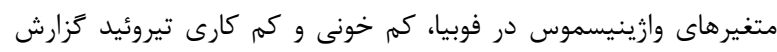

شده است.
يرسشنامه شاخص عملكرد جنسى زنان: جهت بررسى عملكـرد

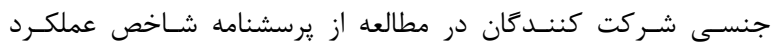

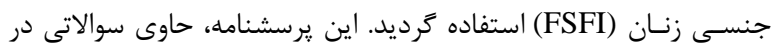

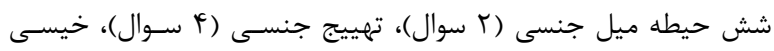

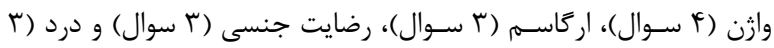

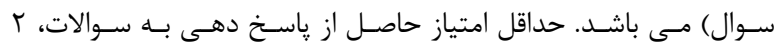

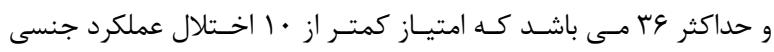

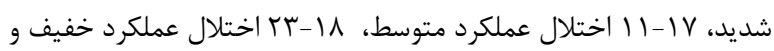

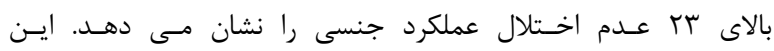

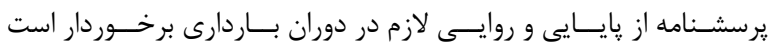

روش تحليل داده ها

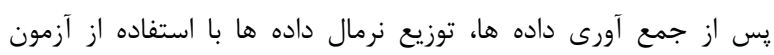

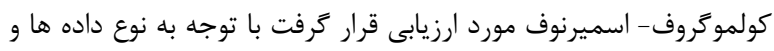

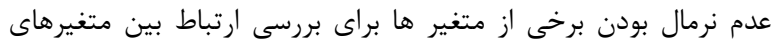

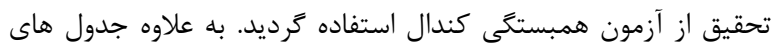

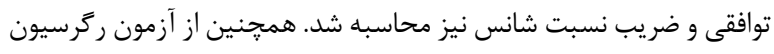

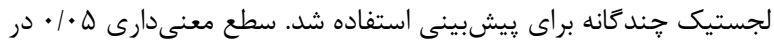

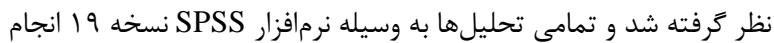

\section{يافته ها}

در جدول ا نتايج شاخص هاى دموكرافيك شركت كنند مان گزارش شده

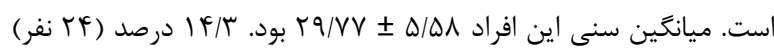

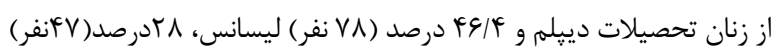
فوقليسانس و س/11/ درصد (19 نفر ) دكترى بوده است. مدت زمات زمان تأهل

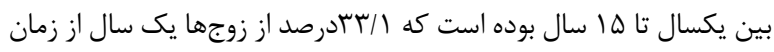

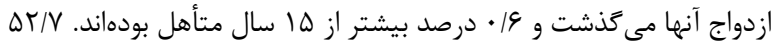

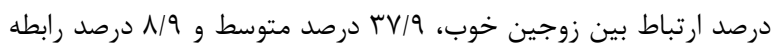

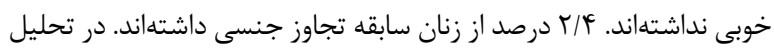

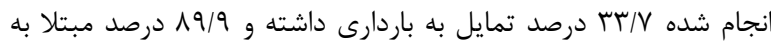

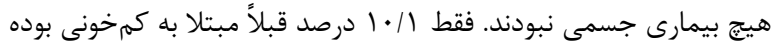

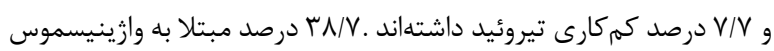

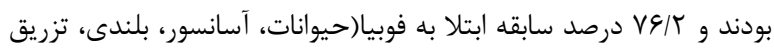
و خون) داشتهاند.

جدول ا. وضعيت شاخص ها دموكر افيك شركت كنند اندان

\begin{tabular}{|c|c|c|c|}
\hline \multicolumn{2}{|c|}{ آماره } & \multirow{2}{*}{ وضعيت } & \multirow{2}{*}{ شاخص } \\
\hline درصد & تعداد & & \\
\hline$T / F$ & $f$ & بله & \multirow{2}{*}{ سابقه تجاوز جنسى } \\
\hline $9 \vee / 9$ & 194 & خير & \\
\hline $\mid F / \pi$ & TF & دييلم & \multirow{4}{*}{ تحصيلات } \\
\hline 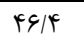 & vi & ليسانس & \\
\hline TA & iv & فوق ليسانس & \\
\hline $11 / \pi$ & 19 & دكترى & \\
\hline
\end{tabular}


بر اساس متغير وابسته يى مىبريم. نتايج اين جدول نشان مىدهد دقت

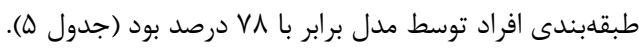

جدول ه. نتايج جدول طبقدبندى

\begin{tabular}{|c|c|c|c|}
\hline \multicolumn{3}{|c|}{ بيش بين شده } & \multirow{3}{*}{ مشاهده شده } \\
\hline \multirow[t]{2}{*}{ درصد درستى } & \multicolumn{2}{|c|}{ وازينيسموس } & \\
\hline & بله & خير & \\
\hline$\Delta T / T$ & r & ry & خير \\
\hline $9 \% / T$ & $9 \mathrm{~V}$ & 9 & بله \\
\hline vı & & & درصد كلى \\
\hline
\end{tabular}

همجنين حساسيت مدل يعنى درصد افراد مبتلا به بهطور دقيق با مداق

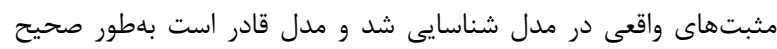

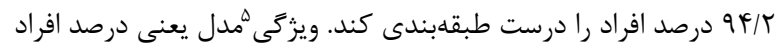

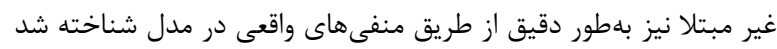

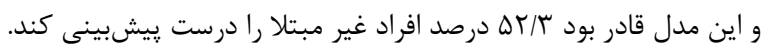

\section{بحث و نتيجه گيرى}

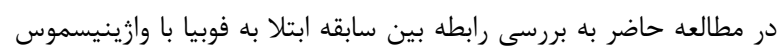

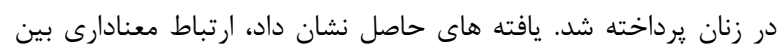

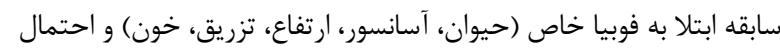

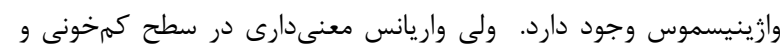

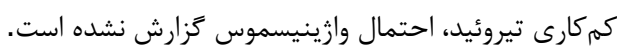

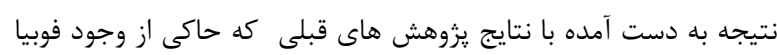

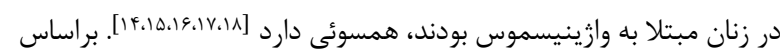

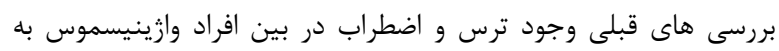

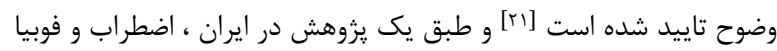

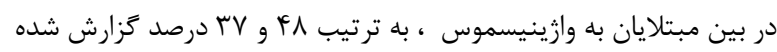

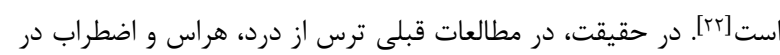

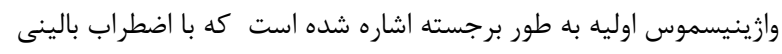

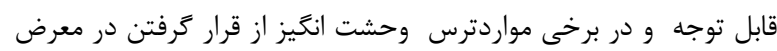

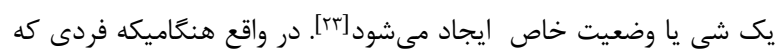

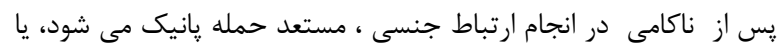

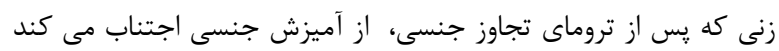

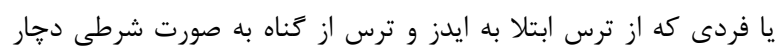

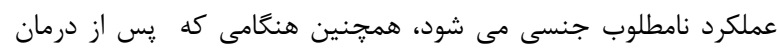

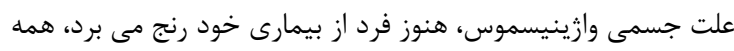

Sensitivity

Specificity
جدول r. ضرايب توافقى در متغيرهاى وازينيسموس در فوبيا، كم خونى و كم كارى تيروئيد

\begin{tabular}{|c|c|c|c|c|c|c|c|c|c|c|}
\hline \multicolumn{3}{|c|}{ كم كارى تيروئيد } & \multicolumn{3}{|c|}{ كم خونى } & \multicolumn{3}{|r|}{ فوبيا } & \multirow{2}{*}{\multicolumn{2}{|c|}{ متغير }} \\
\hline كل & خير & بله & كل & خير | | | | & بله & 5 & خير | خير & بله & & \\
\hline 90 & 4. & $\Delta$ & $9 \Delta$ & $\Delta F$ & 11 & 90 & re & ri & خير & Is \\
\hline 1.4 & 90 & 1 & $1 . r$ & $9 \mathrm{~V}$ & 9 & $1 . r$ & 4 & $9 V$ & بله & 3 \\
\hline 114 & 190 & ir & 191 & $\mid 01$ & iv & 191 & F. & ITM & ل & \\
\hline
\end{tabular}

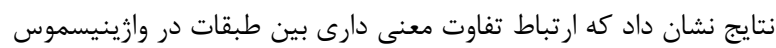

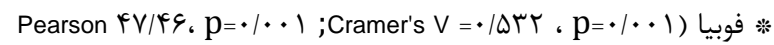
وجود دارد اما در طبقات وازينيسموس * * كم خونى (Chi-Square=

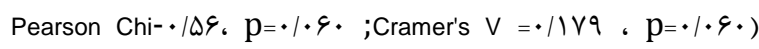
و وازينيسموس ** كم كارى تيروئيد (Square= ( Pearson Chi-Square=•/·1، p=•/914\%;Cramer's V دار نبود. در ادامه تحليل، نتايج ركرسيون لجستيك קند اردانه انجام شد. نتايج آزمون

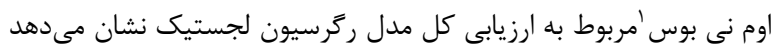

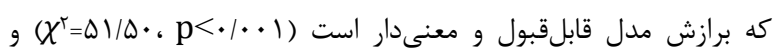

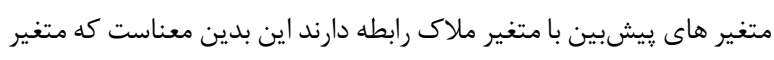

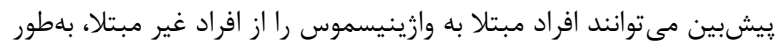
معنادارى از يكديكر تفكيك كنند.

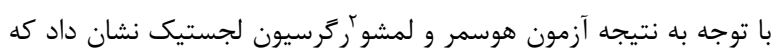

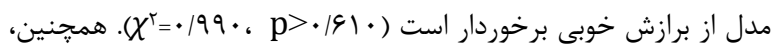

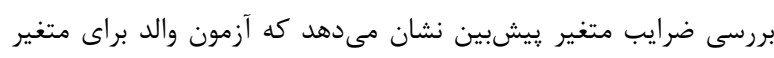

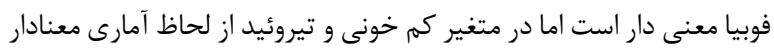

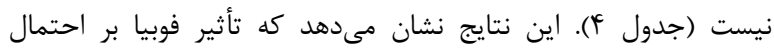

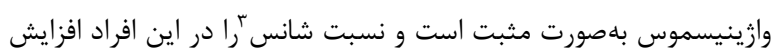

مى دهد.

جدول F. ضرايب ركرسيون لوجستيك براى پيش بينى وازينيسموس

\begin{tabular}{|c|c|c|c|c|c|c|c|c|}
\hline \multicolumn{2}{|c|}{ ه9 درصد نسبت شانس } & \multirow{2}{*}{ نسب شانس } & \multirow{2}{*}{ sig } & \multirow{2}{*}{ df } & \multirow{2}{*}{ ضريب } & \multirow{2}{*}{ S.E } & \multirow{2}{*}{ B } & \multirow{2}{*}{ متغير } \\
\hline كران بالا & كران يايين & & & & & & & \\
\hline - /AQT & $1 . \pi r$ &.$/ \Delta A$ &.$/ . .1$ & 1 & $r T / F \mid G$ & - אFq & $r / A F q$ & فوبيا \\
\hline १/१९. & $\cdot|\Lambda|$. & $r /$ rTa & $\cdot N \cdot \Delta$ & 1 & T/GTV & . $/ 9 \pi T$ & $1 / \cdots v$ & كم خونى \\
\hline H/QTT & . & I/KIT &.$/ W{ }^{2}$ & 1 & . . . & $.19 \mathrm{VT}$ & -/194 & كم كارى \\
\hline
\end{tabular}

جدول طبقهبندى خروجى ركرسيون لجستيك عملكرد مدل و قدرت

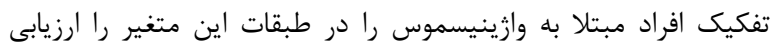

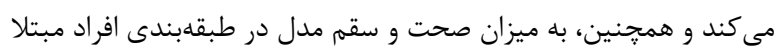

. Omnibus test

Hosmer and Lemeshow Test

? Odd Ratio 


$$
\text { منابع مالى: اين طرح با هزينه محقق انجام يذيرفت. }
$$

منابع

1. Fathi E, Esmaeily M, Farahbakhsh K, Daneshpour M. Iranian Satisfied Marriage Model: A qualitative Grounded Theory Study. Journal of Research in Psychological Health. 2017; 10(2): 10-26. [Persian].

2. Tajikesmaeili A, gilak Hakim abadi M. sexual functions and marital adjustment married woman with Multiple Sclerosis. Journalof Research in Psychological Health. 2017; 10(2): 1-9. [Persian].

3. Pacik PT. Understanding and treating vaginismus: a multimodal approach. IUGJ 2014 25(12): 1613-20.

4. Bertolasi L, Frasson E, Cappelletti JY, Vicentini S, Bordignon M. Botulinum neurotoxin type A injections for vaginismus secondary to vulvar vestibulitis syndrome. Obstet Gynecol Int J 2009; 114 [5]: 1008-16

5. Mohamadi A. The effect of cognitive-behavioral therapy in reducing anxiety and increasing sexual function and marital satisfaction in patients with vaginismus. Master's thesis. General Psychology, University of Isfahan. 2012.

6. Gammoudi N, Affes Z, Mellouli S, Radhouane K, Dogui M. The diagnosis value of needle electrodeelectromyography in vaginismus. Sexologies 2016; 25[4]: 57-60.

7. Konkan R, Bayrak M, Gonullu OG, Senormanci O, Sungur MZ. [2012]. Sexual function and satisfaction of women with vaginismus. Düşünen Adam 2012; 25[4]: 305-11

8. McCool ME, Theurich MA, Apfelbacher C. Prevalence and predictors of female sexual dysfunction: a protocol for a systematic review. Systematic Reviews 2014; 3[75]: 344-9.

9. Möller L, Josefsson A, Bladh M, Lilliecreutz C Sydsjö G. Reproduction and mode of delivery in women with vaginismus or localised provoked vestibulodynia: a Swedish register-based study. Br J Obstet Gynaecol 2012; 122(3): 329-34.

10. Hamidi S, Shareh H, Hojjat S. Comparison of early maladaptive schemas and attachment styles in women with vaginismus and normal women. IJOGI 2015; 18[155,156]: 9-18. [Farsi].

11. Hamid N, Dehghanizadeh Z, Asghar Firuzi A. Effects of Cognitive-Behavioral Therapy on Sexual Function in Women with Vaginismus Disorder. Iranian Journal of Obstetrics, Gynecology \& Infertility. 2012; 15(20).

12. Basson R, Althof S, Davis S, Fugl- Meyer K, Goldstein I, Leiblum S et al. Summary of the recommendations on sexual dysfunctions in women. J Sex Mes 2004; 1: 24-34.

13. Sadock, B J, sadock, V A. (2015). Kaplan \& sadock's synopsis of psychiatry: behavioral
نشان دهنده ارتباط اين وازينيسموس با اضطراب مى باشد [ها] و باتوجه

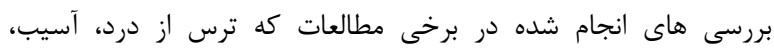

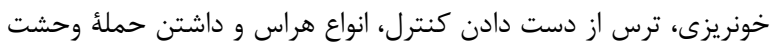

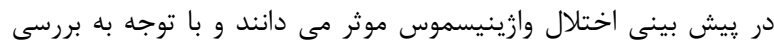

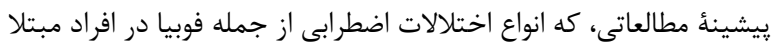

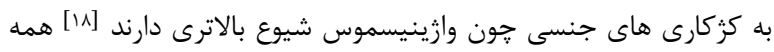

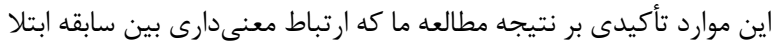

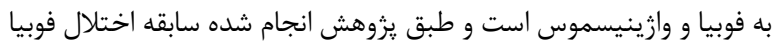

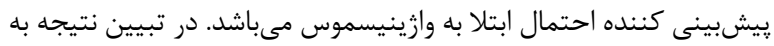

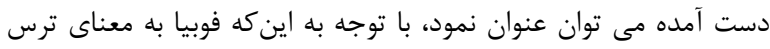

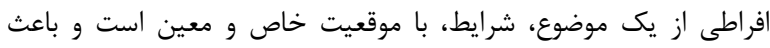

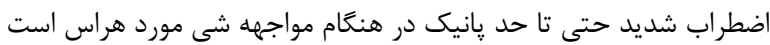

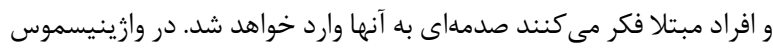

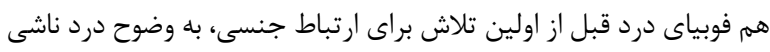

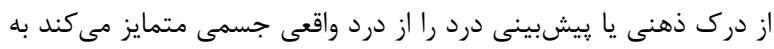

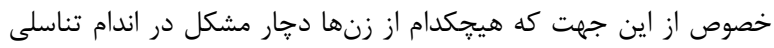
نبودند [rF]

از آنجايى كه كمخونى و كمكارى تيروئيد نيز از جمله بيمارىهايى بودند

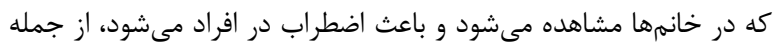

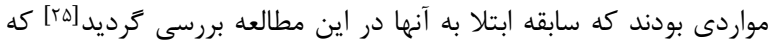

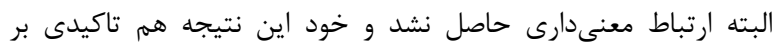

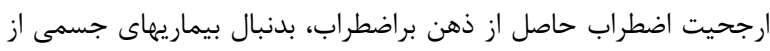
جمله كم خونى و كم كارى تيروئيد است.

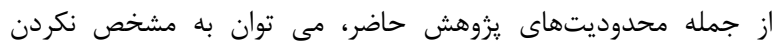

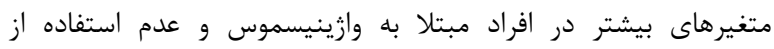

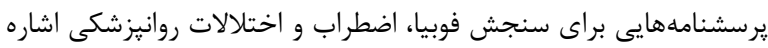
كرد ، اكرجه مصاحبه بالينى توسط روانيزشك انجام شده است.

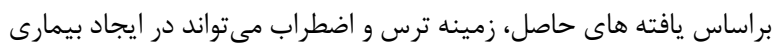

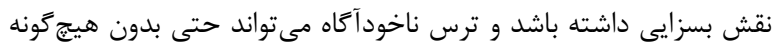

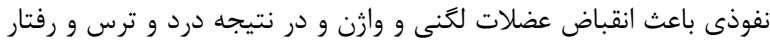

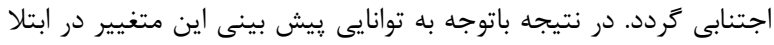

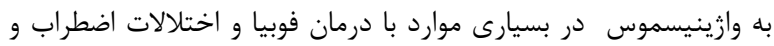

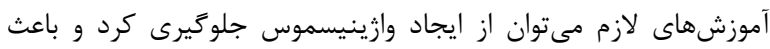
رضايت در رابطه جنسى زوجين كرديد.

تشكر و قدردانى: بدينوسيله از جناب آقاى دكتر ابوطالب صارمى، آقاى

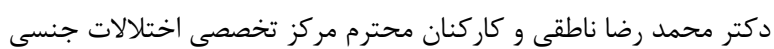

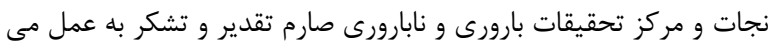
آيد.

$$
\text { تاييديه اخلاقى: اين طرح مورد تاييد كميته اخلاق (IEC) مركز }
$$

$$
\text { تعارض منافع: در اين مطالعه تعارض منافع وجود نداشت. }
$$


sciences / clinical psychiatry. Translated by Farzin Rezaei - Arjmand Publications.

14. Hartman D. Therapy of Vaginismus by Hypnotic Desensitization. Journal of Heart Centered Therapies. 2010; 13(1): 107-8

15. Mohamadi A. The effect of cognitive-behavioral therapy in reducing anxiety and increasing sexual function and marital satisfaction in patients with vaginismus. Master's thesis. General Psychology, University of Isfahan. 2012.

16. Fadul R, Garcia R, Zapata-Boluda R, ArandaPastor C, Brotto L, Parron-Carreño T \& AlarconRodrigue R. Psychosocial Correlates of Vaginismus Diagnosis: A Case-Control Study. Journal of Sex \& Mari Marital Therapy. 2019; 7: 1-11.

17. Rajaee, F, Eshghi, R. The effect of behavioralcognitive hypnotherapy on improving anxiety and sexual performance ofvaginismuspatients. Clinical Psychology, 2017; 9 (4): 55-69.

18. YILDIRIM, E A, YILDIRIM, M H , KARAŞ, $\mathrm{H}$. Prevalence of Depression and Anxiety Disorders and Their Relationship with Sexual Functions in Women Diagnosed with Lifelong Vaginismus. Turkish Journal of Psychiatry 2019;30: 1-7.

19. Foroutan S K, jadid milani M. The Prevalence of Sexual Dysfunction among Divorce Requested. Daneshvar Med 2009; 16(78): 39-44. [Farsi].

20. Mohammadi Kh, Heydari M, Faghihzadeh S. Validity of the Persian version of the scale Female Sexual Function Index-FSFI As the female sexual function index. Journal of Payesh 2008; 7 (2): 269- 278.

21. Reissing ED, Binik YM, KHALIF S, Cohen D, Amsel R. Etiological correlates of vaginismus: sexual and physical abuse, Sexual knowledge, sexual self- schema. And relationship adjustment. J Sex Marital Ther 2003; 29: 47-59.

22. Amin Esmaeli M, Azar M, iranpour C. The prevalence of anxiety symptoms in patients with vaginismud referred to a private psychiatric clinic in Tehran (2001-2002) . J Reprod Infertil 2003;4: 156-163.

23. Reissing ED , Binik YM, Khalife S, Cohen D, Amsel R. Vaginal spasm, pain, and behavior: an empirical investigation of the diagnosis of vaginismus. Arch Sex beav 2004; 33: 5- 17.

24. Hawton K, Catalan J. Sex therapy for vaginismus : characteristics of couples and treatment outcome. Sex Marital Ther 1990; 5: 39-48.

25. Nabil Mhiri M, Smaoui W. Bouassida M. Chabchoub K, Masmoudi J, Hadjslimen M et al. Unconsummated marriage in the Arab Islamic world : Tunisian experience. Sexologies 2013;22: 71-76. 